\title{
Survivors Teaching Students: Increasing awareness about ovarian cancer
}

by Margaret Fitch, RN, PhD, Alison McAndrew, BA, RAP, Fran Turner, MS, Elisabeth Ross, MHSc, and Iris Pison, BSc, MBA

\begin{abstract}
New evidence has emerged concerning the persistent presence of a combination of symptoms that can be indicative of ovarian cancer. Professionals need to be aware of this evidence and incorporate it into their practice. Ovarian Cancer Canada (OCC) has implemented an innovative program in selected Canadian universities, as a method to educate undergraduate medical and nursing students about ovarian cancer. Survivors Teaching Students has been offered to 3,620 undergraduate students. This article presents the evaluation of the program using pre and post session surveys. Overall, students reported a change in knowledge related to the progression of ovarian cancer, symptoms of ovarian cancer, risk factors for the disease, and perspectives about what a woman with ovarian cancer might feel on being diagnosed. Having survivors provide the classroom session brought "a face and a voice" to the issue of ovarian cancer for the students.
\end{abstract}

\section{Introduction}

Women in Canada have a one-in-70 lifetime risk of being diagnosed with ovarian cancer (NCIC, 2009). Approximately 2,700 are diagnosed every year. Ovarian cancer is the most serious gynecologic cancer-the fifth most common cancer in women, but the fourth most common cause of mortality. It has been called "the disease that whispers" because the signs and symptoms have been seen as vague and subtle, resulting in late-stage diagnosis when the survival rate is only 20\% (Jayde, White, \& Blomfield, 2009). Recent studies, however, have identified the persistent presence of a combination of symptoms (e.g., bloating, increased abdominal girth, and urinary symptoms) can be indicative of ovarian cancer (Bankhead et al., 2008; Devlin et al., 2010; Goff, Mandel, Melancon, \& Muntz, 2004; Hamilton, Peters, Bankhead, \& Sharp, 2009). In the absence of a reliable screening test (Andersen et al., 2008; Jayde et al., 2009; Rossing, Wicklund, Cushing-Haugen, \& Weiss, 2010), the presence of this combination of symptoms warrants clinical investigation for ovarian cancer. Health care professionals not only need to be aware of this new evidence, but they also must incorporate it into their practice. Educational initiatives are required to assist in achieving this goal, both at the undergraduate and post-graduate levels.

\section{Background}

The need for increased awareness on the part of health care professionals about signs and symptoms of ovarian cancer, and the familial risk factors that might indicate a predisposition to ovarian or breast cancer, was identified in a national survey of family physicians (Gray, Chart, Carrol, Fitch, \& Cloutier-Fisher, 1999) and a national survey of ovarian survivors (Fitch, Gray, DePetrillo, Franssen, \& Howell, 1999). In particular, survivors described the challenges in seeking professional help for symptoms they were experiencing and obtaining a definitive diagnosis (Fitch, Deane, Howell, \& Gray, 2002). These findings were presented at the first Canada-wide conference on ovarian cancer, Ovarian Cancer Forum '99, and provided an impetus for initiatives in public and professional education. The survivors, researchers, health care professionals and other stakeholders at the conference laid out a threefold mission for Ovarian Cancer Canada: 1) support women living with the disease and their families, 2) raise awareness in the general public and with health care professionals, and 3) fund research for early detection techniques and improved treatments. These directions have guided the organization in planning programs and community outreach since that time (see http://ovariancanada.org).
The initial effort to raise awareness among health care professionals was aimed primarily at family physicians. Ovarian Cancer Canada developed an online course in partnership with McMaster University (Ontario) and Memorial University (Newfoundland). This course is one provided by http://www.mdcme.ca/cmecourse_info.asp?Id=42 and is available on an ongoing basis free of charge to family physicians. Currently a face-to-face course for family physicians that uses survivors is being piloted by OCC.

The next awareness initiative extended the efforts of Ovarian Cancer Canada toward students in the health disciplines. The initiative took the form of a new program in Canada entitled, Survivors Teaching Students. This article will describe the program and present the evaluation results from its initial two years of implementation in Canadian universities with medical and nursing undergraduate students. It is anticipated this type of program could be of benefit to other jurisdictions and disease sites.

\section{Survivors Teaching Students: Program description}

\section{Original program}

The program called Survivors Teaching Students (STS) Saving Women's Lives was initially introduced in 2002 in the United States by Betty Reiser at the University of Medicine and Dentistry of New Jersey. The program eventually became a signature program under

\section{About the authors}

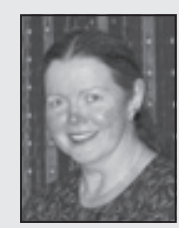

Address for correspondence: Margaret Fitch, $R N$, PhD, Odette Cancer Centre, 2075 Bayview Ave., Toronto, ON M4N 3M5. Tel: 416-480-5891; Fax: 416-480-7806; Email: marg.fitch@sunnybrook.ca

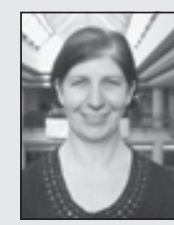

Alison McAndrew, BA, RAP, Odette Cancer Centre, 2075 Bayview Ave., Toronto, ON M4N 3M5. Email: alison.mcandrew@sunnybrook.ca

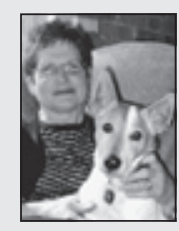

Fran Turner, MS, Ovarian Cancer Canada, 145 Front Street East, Suite 101, Toronto, ON M5A 1E3. Email: fturner@ovariancanada.org

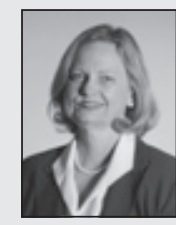

Elisabeth Ross, MHSc, CEO, Ovarian Cancer Canada, 145 Front Street East, Suite 101, Toronto, ON M5A 1E3.Email: eross@ovariancanada.org

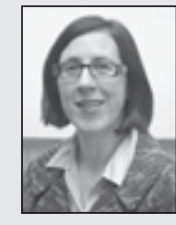

Iris Pison, BSc, MBA, Ovarian Cancer Canada, 145 Front Street East, Suite 101, Toronto, ON M5A 1 E3. Email: ipison@ovariancanada.org 
the auspices of the Ovarian Cancer National Alliance, a U.S. organization that advocates on behalf of women with ovarian cancer (www.ovariancancer.org). The program is now offered in 60 medical schools and universities across the United States.

The STS program was designed to prepare women who have been diagnosed with ovarian cancer to give presentations about their experiences with the disease to students in the health professions. The survivors present as a panel of three. The students are exposed to the key ideas that the majority of ovarian cancer cases are not diagnosed until the disease is in the late stages when survival is compromised. A major reason for this situation is that symptoms that are present may not be recognized as heralding ovarian cancer. Additionally, women at higher risk may not be identified or monitored appropriately (Ryerson et al., 2007; Bankhead et al., 2008). These ideas are incorporated by the survivors into their stories about their experiences with ovarian cancer. STS brings the faces and voices of ovarian cancer survivors into the classrooms of undergraduate medical, nursing, social work, and pharmacy students. The presentations offer a cancer reality or a living example of the cancer experiences in the classroom. The presentations are designed to facilitate learning, early in a student's health professional career experience, about the views or perspectives of patients and survivors. They are also designed to sensitize the students to breaking bad news and talking about statistics in meaningful ways when prognosis is discussed.

\section{Program brought to Canada}

Ovarian Cancer Canada brought the STS Program to Canada in 2006. The content was appropriately "Canadianized" and a cadre of survivors was recruited and trained to be presenters. Betty Reiser directly trained the first 70 Canadian survivors while OCC assumed responsibility for the training since that time. The actual training workshop included two primary elements. The first element was learning how to present and reinforce the key messages about ovarian cancer (see below). The second element was fine tuning a written story the survivor prepared about her symptom experience, how she was diagnosed, her family history, and her progress through treatment. The stories incorporate how the women felt and their perspectives about interaction with health care professionals. During the training, the survivors practised giving their presentations and responding to questions from an audience. The training session usually lasted 50 minutes.

\section{Selection of the survivors to be trained}

A call for survivor volunteers interested in participating in the STS program was communicated through OCC's publications (Seeds of Hope and e-news). The invitation identified the specific locations since survivors are needed for training in cities with medical and nursing schools. It was desirable to have the survivors who present to students reflect a range of stages at diagnosis and a variation in the length of survivorship. While it is desirable to have women who are not coping with active disease cancer, the reality is that many of the survivor volunteers are likely to experience recurrence and some have died during the program. Women who are interested in being part of the program were asked to contact the OCC program manager and to write and submit the story of their cancer experience in advance of an interview. The interview included reviewing the woman's story and talking about the guidelines of the program. It is important to help the woman understand what will be required of her if she participates in Survivors Teaching Students.

Feedback from the survivor volunteers about the STS training workshop and learning how to present their stories has been very positive (McAndrew, Fitch, Turner, \& Ross, 2008). They saw the program overall as an opportunity to influence future health care professionals about ovarian cancer and symptoms. In particular, the training helped them to feel confident in presenting their personal stories in front of the student audience. [See inset A regarding volunteer perspectives.]

\section{STS program delivery}

Once permission has been granted by the university faculty for the presentation in the classroom, each session is offered in the following format:

- Each overall presentation lasted about one hour with the students.

- Each presentation typically included three presenters who are ovarian cancer survivors. One acted as the facilitator for the session. The presentation included women with different backgrounds and experiences, as was feasible. In many cases, most of the women who presented were diagnosed at a late stage, but it is valuable to include women diagnosed at an early stage as well.

- At the presentation, the facilitator provided a brief introduction and then each presenter told her story, illustrating the difficulty of early diagnosis and what happened to her as a result. The survivor's story puts a face and voice to the disease, which is thought to be a powerful tool in increasing students' understanding and students had an opportunity to hear about the psychosocial aspects of ovarian cancer.

- After the presentations, a dialogue led by a survivor facilitator, opened a communication between the presenters and the students and enabled a direct and substantive interaction.

- Students were given a brief pre- and post-test to assess their understanding of the disease and the value of the presentation.

- The presentation was offered free of charge to health professional schools.

\section{Key messages shared during the presentation}

There are key messages the STS program aims to deliver. It was not expected that every presenter will address each of the points, but the entire classroom presentation to the students was conceptualized as the vehicle for these messages to be emphasized. The messages about symptoms are central to the goals of the program. Each

\section{Inset A. Survivor volunteer perspectives regarding STS}

The motivation of the survivors to participate in the program I wanted to feel that I'm doing something that may help women of the future-especially as I carry the BRCA2 mutated gene. I want to try to have some impact on early detection for the sake of my grown children.

Given my positive experience through the pre-diagnosis stage, I felt it would help other medical personnel to know how important it is to: (a) be able to quickly identify ovarian cancer, b) respond in a positive caring way,

I have been the recipient of so much during my illness and I want to give back.

How the survivors would define success of the program If my story, along with others, makes an impact on future medical doctors, so that they are more attuned to women's concerns and more likely to include ovarian cancer as a "rule out" for a wide variety of signs/symptoms.

to sensitize [medical students] to the subtle signs of ovarian cancer and to patients' needs/fears at the time of diagnosis and throughout treatment.

Opportunity to share my story.

The expectations the survivors have for this program Awareness and openness in the students to the stories of their patients.

Bring ovarian cancer into a "standard differential" for obscure abdominal signs in women.

That the students have heard our message. 
survivor presenter focused on the aspects of her story that emphasize and reinforce these key messages. If certain points are not discussed by the specific presenters, the facilitator will raise them in the discussion that takes place with the students following the individual presentations. The key messages included in this program were:

- Ovarian cancer has the highest mortality of all the gynecologic cancers and is one of the five leading causes of cancer death among women in Canada.

- The majority of women diagnosed with ovarian cancer are at advanced stages.

- Currently, there is no reliable screening test for the early detection of ovarian cancer.

- When detected in early stages, the survival rates for ovarian cancer greatly improve.

- The symptoms of ovarian cancer include:

- swelling or bloating of the abdomen;

- pelvic discomfort or heaviness;

- back or abdominal pain;

- fatigue;

- gas, nausea, indigestion;

- change in bowel habits;

- emptying the bladder frequently;

- unusual vaginal bleeding; and

- weight loss or weight gain;

- If a woman presents with any of these symptoms, persisting for three weeks or more, ovarian cancer needs to be considered.

- If a woman presents with signs and symptoms suggestive of ovarian cancer, a complete pelvic exam, a transvaginal ultrasound and a CA125 blood test should be performed.

- If ovarian cancer is suspected, the women must be referred to a gynecologic oncologist.

- Women with a personal or family history of ovarian, breast, or colorectal cancer may be at higher risk for ovarian cancer.

- Although the statistics around ovarian cancer outcomes are not good, each woman's experience is unique. Sensitivity is important when communicating with patients.

\section{Evaluation approaches}

The evaluation of student learning was achieved through administration of pre-post surveys. Prior to the beginning of the classroom session, students were asked to complete a short survey and submit it to the session facilitator. No one was asked to attach a name to the surveys. Following the presentation by the survivors and the overall discussion, the students were asked to complete a second survey and submit it to the facilitator. The facilitator sent all data sheets to the research coordinator in Toronto.

The students were also invited to complete a second post-presentation survey online six months following the classroom session. Mention was made of the online survey at the end of the classroom session and an electronic reminder was sent to each student six months later. Students were given an online address for access to the survey.

The surveys were designed for the purpose of this evaluation. The pre-post classroom session survey focused on knowledge items about ovarian cancer, risk factors, symptoms, assessment approaches, and understanding of patient concerns. These items accounted for 11 questions (see Tables 3 and 4). The post survey also included three additional items concerning the effectiveness of the teaching approach. Response options for these items ranged from strongly agree, agree, disagree, strongly disagree, as well as the option uncertain. One other item asked students to list symptoms of ovarian cancer and the opportunity was given to add an open-ended response at the end of the survey. The online survey was the same as the immediate post-session survey.

\section{Analysis}

The analysis was completed for each class as a group. The analysis of the pre-post session survey was descriptive. Frequency distribu- tions and percentages for each of the item responses were calculated for medical and nursing students separately. The Gynecologic Cancer Foundation (2007) announced a national consensus on ovarian cancer symptoms: bloating, pelvic or abdominal pain, difficulty eating or feeling full quickly, urinary symptoms (urgency or frequency). These four symptoms were used to code the data from the survey item asking the student to "list three symptoms, which, if a woman experienced persistently, would lead you to consider ovarian cancer." When a student answered the question with one of the four symptoms, their answer was coded as "yes." The content from the open-ended question was reviewed and collated. Comments were grouped together based on a simple content analysis of common perspectives.

\section{Results}

Sample and response rates

Between the fall of 2006 and March of 2009, STS sessions were held in seven Canadian faculties of medicine and 12 faculties of nursing. Thirty-five sessions were held with 798 medical students in attendance; 35 sessions were held with 2,822 nursing students. A total of 94 survivor volunteers have been trained to offer STS sessions across Canada. At present, 78 volunteers are active in the STS program. The attrition in volunteers has been primarily a direct result of mortality.

The overall response rates for the pre- and post-surveys were $41.4 \%$ and $43.0 \%$ respectively (see Table 1 ). The response rate for the six-month online follow-up survey was $19 \%$ of those who provided e-mail addresses at the time of the initial classroom survey.

\section{Knowledge}

Across all knowledge items, the proportion of respondents who had correct answers improved after the classroom presentation session. Table 2 presents the proportion of individuals who agreed with each knowledge statement. Clearly, students gained a significant understanding and appreciation for the perspectives of survivors and for the challenges they face. Their knowledge about salient symptoms also improved (Table 3 ). Of note, responses to items regarding the existence of a screening test for ovarian cancer and presence of symptoms at the time of early stage disease reflect continuing knowledge gaps.

\section{Effectiveness of teaching approach}

Both medical students and nursing students indicated high levels of agreement regarding the effectiveness of the teaching approach (see Table 4). They found the stories survivors told about their experience helpful in learning about symptoms and communicating with

\begin{tabular}{|l|c|c|c|c|}
\hline \multicolumn{4}{|l|}{ Table 1. Selected sample observations } \\
\hline & \multicolumn{2}{|l|}{ Medical students } & Nursing students \\
\cline { 2 - 5 } & Number & $\%$ & Number & $\%$ \\
\hline $\begin{array}{l}\text { Students recorded as in } \\
\text { attendance at the class } \\
\text { presentations }\end{array}$ & 798 & 100 & 2,822 & 100 \\
\hline Pre-surveys submitted & 344 & 43 & 1,156 & 41 \\
\hline Post-surveys submitted & 352 & 44 & 1,203 & 42.6 \\
\hline $\begin{array}{l}\text { Males who submitted } \\
\text { pre-survey }\end{array}$ & 121 & $35.2 *$ & 87 & $7.5 *$ \\
\hline $\begin{array}{l}\text { Females who submitted } \\
\text { pre-survey }\end{array}$ & 215 & $62.5 *$ & 1,027 & $89 *$ \\
\hline Online surveys completed & 31 & 3.9 & 59 & 2.1 \\
\hline * Proportion is calculated out of all who submitted. & \\
\hline
\end{tabular}


patients. Both groups perceived having the survivor presentation was an important adjunct to their academic studies. Examples of the written comments offered by students include:

- I will be aware of the early symptoms so, as a nurse, I can help my patients to take appropriate measures to see a physician.

- Will make me more aware of some of the ways ovarian cancer can present-realize the importance of following up on vague symptoms.

- Listen to the patient and notice signs of ovarian cancer-dig deeper, do not just assume stomach pain.

- Communicate more effectively in the future.

- This helped me realize how important it is to communicate with your patients and how sympathetic to be.

- I won't ignore a patient's concerns. I will pay attention to my patients and listen to what they have to say.

- Try to put myself in patient's shoes-be sensitive in diagnosis and in treatment.

- It will influence the way I approach communication of sensitive information to patient.

- As a nurse, I am now aware of the symptoms and how it feels to have cancer based on the presentation, so I can be more understanding towards patients.

\section{Discussion}

Survivors Teaching Students was heralded as a successful program in United States when OCC decided to introduce it into the Canadian environment. Adapting the existing program was seen as a reasonable approach to save effort and have a program available sooner than if one were designing an entirely new program from the beginning. A formal evaluation of the Canadian program was important because evaluation had not been incorporated into the U.S.based program offerings. OCC has a stated commitment to ensuring its programs are effective and, therefore, to evaluating all its programs, as they are implemented.

The format of the evaluation, pre and post classroom session survey, worked reasonably well in terms of program feedback. The response rates were acceptable (Balajti, Daragó, Ádány, \& Kósa, 2010).
Unfortunately, the six-month follow-up survey approach was not successful. The major reasons this approach failed was that many students did not provide an email address at the end of the classroom session. Those who did provide an email address were sent a reminder invitation at six months. However, a fair proportion of the reminders were returned as undeliverable. This may speak to the mobility of the student population. As a result of the poor return at six months, the findings can only be discussed regarding the immediate effect of the classroom session (pre/post survey).

To have survivors presenting within medical/nursing classrooms offered a unique perspective for the students and was seen by them as an effective teaching approach. The students indicated they now had a real person-a face and voice-with which to associate the ovarian cancer story. One could argue this would provide a lasting memory for the students and influence their future practice behaviour as professionals. The individual who has travelled the cancer journey brings an element of credibility to the comments and narratives that are shared and could be considered a "champion." The use of local champions is seen as an effective knowledge translation strategy (Wright, Simunovic, Coates, \& Fitch, 2007). Given the training has occurred, the presentation can offer an engaging first-hand experience. However, this hypothesis about practice change was not tested specifically within the context of this current evaluation.

There was evidence in the evaluation results that a change in knowledge occurred for the students. This change occurred especially with regards to the progression of ovarian cancer, symptoms of ovarian cancer, risk factors for the disease, and perspectives about what women with ovarian cancer might feel on being diagnosed. Knowledge about screening for ovarian cancer and the presence of symptoms at an early stage of the disease did not see the same magnitude of change as the other knowledge items. The information differentiating the concepts of screening in well populations versus early detection through symptom identification is a challenge to present clearly. Students expressed a clear indication their understanding about women's perspectives had been influenced by the presentations and interaction.

Table 2. Knowledge about ovarian cancer: Before and after session

\begin{tabular}{|c|c|c|c|c|}
\hline \multirow{3}{*}{ Item } & \multirow{2}{*}{\multicolumn{2}{|c|}{$\begin{array}{c}\text { Medical Students } \\
\text { Responses for strongly } \\
\text { agree and agree (\%) }\end{array}$}} & \multirow{2}{*}{\multicolumn{2}{|c|}{$\begin{array}{c}\text { Nursing Students } \\
\text { Responses for strongly } \\
\text { agree and agree (\%) }\end{array}$}} \\
\hline & & & & \\
\hline & Pre $(\mathrm{N}=344)$ & Post $(\mathrm{N}=352)$ & Pre $(\mathrm{N}=1156)$ & Post $(\mathrm{N}=1203)$ \\
\hline In general I have a basic understanding of ovarian cancer. & 77.5 & 96.3 & 53.7 & 97.5 \\
\hline $\begin{array}{l}\text { Although ovarian cancer is relatively rare, it is one of the } 5 \text { leading causes of } \\
\text { cancer death among Canadian women. }\end{array}$ & 87.4 & 96.0 & 73.6 & 92.6 \\
\hline Women receive a screening test for ovarian cancer during a routine annual exam. & 8.1 & 11.1 & 26.0 & 13.0 \\
\hline The majority of ovarian cancer cases are diagnosed at an early stage. & 3.8 & 2.2 & 9.8 & 5.5 \\
\hline In its early stages, ovarian cancer causes symptoms. & 7.3 & 36.1 & 8.9 & 58.8 \\
\hline $\begin{array}{l}\text { A woman with a family history of breast cancer, colon cancer, or ovarian } \\
\text { cancer may be at increased risk for ovarian cancer. }\end{array}$ & 95.6 & 98.0 & 85.0 & 97.6 \\
\hline A woman who has had breast cancer may be at an increased risk for ovarian cancer. & 90.4 & 93.5 & 65.0 & 91.5 \\
\hline $\begin{array}{l}\text { If a patient of mine were suspected to have ovarian cancer, I would refer to a } \\
\text { gynecologic oncologist. }\end{array}$ & 90.7 & 98.3 & 82.5 & 98.6 \\
\hline $\begin{array}{l}\text { I can improve survival for a woman with ovarian cancer by being aware of its } \\
\text { risk factors and early symptoms. }\end{array}$ & 94.8 & 99.7 & 94.4 & 99.9 \\
\hline $\begin{array}{l}\text { I understand how a woman with ovarian cancer might feel about being } \\
\text { diagnosed with cancer. }\end{array}$ & 52.2 & 97.9 & 47.2 & 93.5 \\
\hline
\end{tabular}




\section{Implications}

The recruitment and training of the survivor volunteers are key aspects of this program. In particular, the preparation of the survivors to share their stories is a critical element in their comfort and in their capacity to share the story effectively. Without this training, it can be argued the survivors would not be as effective in communicating the key messages. However, in future, there may need to be additional emphasis and clarity about the information the survivors offer regarding screening for ovarian cancer and the appearance of signs and symptoms with early disease.

Given the success of this STS program, based on the evaluation results, it is anticipated other medical and nursing facilities would be willing to incorporate this type of learning experience for their students. Additionally, other faculties such as pharmacy, social work, and psychology might benefit from similar exposure to this program. Given the aging population in Canada, and the increased vulnerability to cancer that accompanies aging, future health care providers need to be aware of survivor perspectives and early detection issues regarding cancer. The challenge, no doubt, will be in finding time in the undergraduate curriculum to insert cancer-spe-

\begin{tabular}{|l|c|c|c|c|}
\hline \multirow{2}{*}{ Table 3. } & \multicolumn{2}{|c|}{$\begin{array}{c}\text { Medical } \\
\text { students }\end{array}$} & \multicolumn{2}{c|}{$\begin{array}{c}\text { Nursing } \\
\text { students }\end{array}$} \\
\hline \multirow{2}{*}{\begin{tabular}{l} 
Symptoms \\
\cline { 2 - 5 }
\end{tabular}} & $\begin{array}{c}\text { Pre } \\
\text { (N=344) }\end{array}$ & $\begin{array}{c}\text { Post } \\
\text { (N=352) }\end{array}$ & $\begin{array}{c}\text { Pre } \\
\text { (N=1156) }\end{array}$ & $\begin{array}{c}\text { Post } \\
\text { (N=1203) }\end{array}$ \\
\cline { 2 - 5 } & \% correct & \% correct & \% correct & \% correct \\
\hline 1st symptom & 57.3 & 60.5 & 31.9 & 58.4 \\
\hline 2nd symptom & 31.1 & 41.2 & 14.0 & 40.1 \\
\hline 3rd symptom & 18.3 & 30.1 & 7.6 & 26.7 \\
\hline
\end{tabular}

\section{References}

Andersen, M.R., Goff, B.A., Lowe, K.A., Scholler, N., Bergan, L., Dresher, C.W., ... Urban, N. (2008). Combining a symptoms index with CA 125 to improve detection of ovarian cancer. Cancer, 113(3), 484-489.

Balajti, I., Daragó, L., Ádány, R., \& Kósa, K. (2010). College students' response rate to an incentivized combination of postal and webbased health survey. Evaluation and the Health Profession, 33, 164-176.

Bankhead, C.R., Collins, C., Stokes-Lampard, H., Rose, P., Wilson, S., Clements, A., ... Austoker, J. (2008). Identifying symptoms of ovarian cancer: A qualitative and quantitative study. British Journal of Obstetrics and Gynecology, 115(8), 1008-1014.

Devlin, S.M., Diehr, P.H., Andersen, M.R., Goff, B.A., Tyree, P.T., \& Lafferty, W.E. (2010). Identification of ovarian cancer symptoms in health insurance claims data. Journal of Women's Health, 19(3), 381-389.

Fitch, M.I., Gray, R.E., DePetrillo, D., Franssen, E., \& Howell, D. (1999). Canadian women's perspectives on ovarian cancer. Cancer Prevention and Control, 3(1), 52-60.

Fitch, M., Deane, K., Howell, D., \& Gray, R.E. (2002). Women's experiences with ovarian cancer: Reflections on being diagnosed. Canadian Oncology Nursing Journal, 12(3), 152-159.

Goff, B.A., Mandel, L.S., Melancon, C.H., \& Muntz, H.G. ( 2004). Frequency of symptoms of ovarian cancer in women presenting to primary care clinics. Journal of the American Medical Association, 291(22), 2705-2712.

Gray, R.E., Chart, P., Carroll, J.C., Fitch, M.I., \& Cloutier-Fisher, D. (1999). Family physicians' perspectives on ovarian cancer. Cancer Prevention and Control, 3(1), 61-67. cific programs. There will also be challenges in finding the balance between presenting a cancer specific knowledge and experiential session and how that might apply across all cancer disease sites.

Finally, although this STS Program was directed at undergraduate students, the program might also be effective for continuing education of health professionals already in practice. With the growing cadre of cancer survivors, there could be a large pool from which to draw candidates for training. Such a program, however, would need to create key messages for the health professional audience based on where they are interacting with patients during the cancer journey. For example, oncology nurses might benefit most from the aspects of survivors' perspectives concerning health care professionals rather than symptoms of early detection.

\begin{tabular}{|l|c|c|}
\hline \multicolumn{2}{|l|}{ Table 4. Effectiveness of teaching strategies } \\
\hline \multirow{2}{*}{ Items of post session survey } & $\begin{array}{c}\text { Medicine } \\
\text { (N=352) }\end{array}$ & $\begin{array}{c}\text { Nursing } \\
\text { (N=1203) }\end{array}$ \\
\cline { 2 - 3 } & $\begin{array}{c}\text { \% responses } \\
\text { strongly agree } \\
\text { and agree }\end{array}$ & $\begin{array}{c}\text { \% responses } \\
\text { strongly agree } \\
\text { and agree }\end{array}$ \\
\hline $\begin{array}{l}\text { The survivors' stories were } \\
\text { effective in teaching me the } \\
\text { symptoms and risk factors for } \\
\text { ovarian cancer }\end{array}$ & 94.6 & 99.6 \\
\hline $\begin{array}{l}\text { The survivors' stories helped me } \\
\text { understand the importance of } \\
\text { how I communicate information } \\
\text { to my patients }\end{array}$ & 98.9 & 98.5 \\
\hline $\begin{array}{l}\text { This presentation was an } \\
\text { important adjunct to my academic } \\
\text { studies on ovarian cancer }\end{array}$ & 97.4 & \\
\hline
\end{tabular}

Gynecologic Cancer Foundation. (2007). Women's Cancer Network Symptoms Consensus Statement. Retrieved from http://www.wcn.org/articles/types_of_cancer/ovarian/symptoms/ concensus_statement.html

Hamilton, W., Peters, T.J., Bankhead, C., \& Sharp, D. (2009). Risk of ovarian cancer in women with symptoms in primary care: Population-based case-control study. British Medical Journal, 339, article number b2998.

Jayde, V., White, K., \& Blomfield, P. (2009). Symptoms and diagnostic delay in ovarian cancer: A summary of the literature. Contemporary Nurse, 34(1), 55-65.

McAndrew, A., Fitch, M., Turner, F., \& Ross, E. (2008). Cancer survivors teaching students in health care. Supportive Care in Cancer, 16, 749(\#22-241).

National Cancer Institute of Canada [NCIC]. (2009). Canadian cancer statistics 2009 (Monograph). Toronto: Author.

Rossing, M.A., Wicklund, K.G., Cushing-Haugen, K.L., \& Weiss, N.S. (2010). Predictive value of symptoms for early detection of ovarian cancer. Journal of the National Cancer Institute, 102(4), 222-229.

Ryerson, A.B., Eheman, C., Burton, J., McCall, N., Blackman, D., Subramanian, S., \& Richardson, L.C. (2007). Symptoms, diagnoses, and time to key diagnostic procedures among older U.S. women with ovarian cancer. Obstetrics \& Gynecology, 109(5), 1053-1061.

Wright, F.C., Simunovic, M., Coates, A., \& Fitch, M.I. (2007). The quality initiative in rectal cancer surgery: A qualitative study of participating surgeons. Journal of American College of Surgeons, 203(6), 795-802. 